\title{
La educación venezolana en tiempos de guerra
}

\section{A educação venezuelana em tempos de guerra}

\section{Venezuelan education in times of war}

\author{
Samuel H. Carvajal Ruíz \\ Paulina E. Villasmil Socorro**
}

\begin{abstract}
RESUMEN
El presente ensayo caracteriza de manera general las acciones unilaterales y coercitivas contra Venezuela, promovidas en estas dos últimas décadas por los gobiernos de Estados Unidos (EE.UU.) y su impacto en las políticas públicas sociales, específicamente las educativas. Se enfatiza en este esfuerzo descriptivo-analítico, en las medidas asumidas por la administración ObamaTrump, cuyos efectos han sido devastadores para la economía del país, con claras consecuencias en la vida cotidiana del pueblo venezolano. La finalidad de tales acciones de guerra, inscritas en la doctrina política de "cambio de régimen", ha sido la de gestar desafección y rechazo de la sociedad hacia la dirigencia política del país y al proyecto político bolivariano, para facilitar la agenda mencionada. El gobierno de los EE.UU. ha utilizado la complicidad de la Organización de Estados Americanos (OEA), así como la conjura de gobiernos de países de la región reunidos en el cartel autodenominado "Grupo de Lima", cuyos rasgos característicos es su obediencia y sumisión a las directrices político-ideológica de los sectores ultraconservadores de los EE.UU. en el poder y sus aliados corporativos fuera de éste. De allí que, se atisban algunos rasgos de la política social de la Revolución Bolivariana, enfatizando en la política educativa en tiempos de profundización de la
\end{abstract}

* Universidad Nacional Simón Rodríguez. Caracas, Venezuela. E-mail: cursosunesr2015@ gmail.com- http://orcid.org/0000-0003-0747-296X

** Universidad Nacional Experimental "Rafael María Baralt”. Venezuela. E-mail: paulinavillasmil@gmail.com - http://orcid.org/0000-0002-7298-741X 
lucha de clases cuya expresión es la hibridación de la guerra en contra del proyecto bolivariano.

Palabras clave: Guerra híbrida. Imperialismo. Revolución Bolivariana. Política educativa. Participación popular.

\title{
RESUMO
}

Este artigo caracteriza de modo geral as ações unilaterais e coercitivas contra a Venezuela, promovidas nestas últimas décadas pelos governos dos Estados Unidos da América (EUA) e seu impacto nas políticas sociais, especificamente as educativas. Se enfatiza neste esforço descritivo-analítico este descritivo-analítico, as medidas assumidas pela administração ObamaTrump, cujos efeitos foram devastadores para a economia do país, com consequências claras na vida cotidiana do povo venezuelano. A finalidade de tais ações de guerra, inscritas na doutrina política de "câmbio de regime", foi de criar descontentamento e rejeição da sociedade em relação à liderança política do país e ao projeto político bolivariano, para facilitar a agenda mencionada. O governo dos EUA utilizou a cumplicidade da Organização dos Estados Americanos (OEA), assim como a conspiração de governos de países da região reunidos no cartel autodenominado "Grupo de Lima”, cujas características são obediência e submissão às diretrizes político-ideológicas dos setores ultraconservadores dos Estados Unidos no poder e seus aliados corporativos fora dele. Assim, vislumbram algumas características da política social da Revolução Bolivariana, enfatizando a política educacional em tempos de aprofundamento da luta de classes cuja expressão é a hibridização da guerra contra o projeto bolivariano.

Palavras-chave: Guerra híbrida. Imperialismo. Revolução Bolivariana. Política educativa. Participação popular.

\begin{abstract}
This essay characterizes in a general way the unilateral and coercive actions against Venezuela, promoted in these last two decades by the governments of the United States (USA) and its impact on social public policies, specifically educational ones. Emphasis is placed on this descriptive - analytical effort, on the measures taken by the Obama - Trump administration, the effects of which have been devastating for the country's economy, with clear consequences on the daily life of the Venezuelan people. The purpose of such actions of war, inscribed in the political doctrine of "regime change", has been to create disaffection and rejection of society towards the country's political leadership and the Bolivarian political project, to facilitate the aforementioned agenda. The U.S. government He has used the complicity
\end{abstract}


of the Organization of American States (OAS), as well as the conspiracy of governments of countries in the region gathered in the self-proclaimed "Lima Group" poster, whose characteristic features are their obedience and submission to political-ideological guidelines of the ultraconservative sectors of the USA in power and its corporate allies outside it. Hence, some features of the social policy of the Bolivarian Revolution are glimpsed, emphasizing educational policy in times of deepening of the class struggle whose expression is the hybridization of the war against the Bolivarian project.

Keywords: Hybrid war. Imperialism. Bolivarian Revolution. Educational policy. Popular participation.

\section{Contexto general de la guerra imperial contra Venezuela}

La actual coyuntura política y económica del país, sometido a mecanismos de guerra no convencional, obliga a repensar todos los ámbitos de las políticas públicas y, de manera especial, el referido al de la educación nacional. Las medidas restrictivas y unilaterales de bloqueo emprendidas por el gobierno de los EE.UU., ha causado severos daños a la economía venezolana que, inevitablemente, impactan en la cotidianidad de todos.

Este hecho se magnifica, por una parte, debido a la alta e histórica dependencia de la economía venezolana a los vaivenes de la política y la economía de los EE.UU. ${ }^{1}$, en su papel hegemónico en la metrópolis capitalista global; pero, además, por considerar éste que Venezuela corresponde a su ámbito de hegemonía geopolítica. ${ }^{2}$ Hasta hace unos años, los EE.UU. era el principal "cliente" (o como se dice ahora, "socio comercial") de las exportaciones venezolanas, concentradas básicamente en los hidrocarburos y sus derivados. Consecuentemente con esto, como segundo dato a resaltar, la significativa inversión en política social realizada en estas dos últimas décadas, derivada fundamentalmente de los ingresos producto de las exportaciones en hidrocarburos.

1 Esta condición de dependencia que opera en varios órdenes de la vida política, económica, social y cultural del país, se inaugura y torna más visible a partir del cambio de matriz económica que se observa en Venezuela a comienzos del siglo XX. Se trata de la conversión de un país con una base económica - productiva agrícola, hacia una economía minero extractivista, con énfasis en la explotación y exportación petrolera.

2 El secular planteamiento de la Doctrina Monroe, ahora actualizada por la agresiva política emprendida por Obama y Trump en contra de Venezuela y sus intereses. 
El Centro Estratégico Latinoamericano de Geopolítica (CELAG), en el informe Las consecuencias económicas del boicot a Venezuela de febrero de 2019, sostiene que:

En el caso de Venezuela la dependencia es aún más crítica pues la oferta interna de bienes es altamente dependiente de la cantidad de divisas disponibles para importar. Venezuela es un país que desde la década del '60 ha profundizado su especialización productiva en el petróleo $\mathrm{y}$, en consecuencia, es altamente dependiente de las importaciones. El dólar es el insumo más importante de la oferta agregada y su sistema productivo depende del financiamiento del exterior para poder seguir reproduciéndose. Sin una entrada neta de dólares que financie el proceso productivo, la economía se achica al compás de la escasez de divisas. El boicot económico que Venezuela está sufriendo ha recrudecido tras la asunción de Nicolás Maduro en 2013, es una muestra de que la integración comercial plena en la globalización tiene efectos secundarios negativos, y entre ellos destacan los riesgos geopolíticos que hoy afectan al país. (CELAG, 2019, p. 1).

Cuando el 8 de marzo de 2015, el entonces presidente de los EE.UU. Barack H. Obama, firmó la Orden Ejecutiva $\mathrm{N}^{\circ} 13.692$, en la que, entre otras cosas, se afirmaba que Venezuela y su actual gobierno "[...] representaba una amenaza inusual y extraordinaria a la seguridad de los EE.UU.", implicaba el reconocimiento imperial a la posibilidad de consolidación del modelo político, social y económico que impulsa Venezuela, fundamentado en la Constitución de la República Bolivariana de Venezuela y explicitado en el Plan de la Patria, que impugna los valores e intereses hegemónicos de las élites del capitalismo global, favoreciendo la repolitización de la sociedad mediante un modelo de democracia directa y popular.

Aquí cabe recordar el divorcio histórico entre el capitalismo y la democracia, que no es otra cosa que la pretensión neoliberal de atar el futuro de la democracia a la "salud" de los mercados. En este sentido, Atilio Boron sostiene que:

La lógica de funcionamiento de la democracia, aún en una forma tan imperfecta como la que existe en el ámbito del capitalismo, es incompatible con la que exige la dinámica de los mercados. Una democracia, por elemental que sea, remite a un modelo ascendente de 
organización del poder social. Este se construye de abajo hacia arriba, sobre la base del reconocimiento de la absoluta igualdad formal y sustantiva y la plena autonomía de los sujetos constituidos del demos que, de ese modo, confluyen en constituir la autoridad política. El mercado, por el contrario, obedece a una lógica descendente: son los grupos poderosos - principalmente los oligopolios - quienes desde su cumbre tienen la capacidad de "construirlo", organizarlo y modificarlo a su imagen y semejanza, y lo hacen arriba hacia abajo con criterios diametralmente opuestos a los que presiden la constitución de un orden democrático. Si en la democracia lo que cuenta es la base sobre la cual reposa la cúspide del sistema, en los mercados los actores cruciales son los que concentran en la cima. (BORON, 2019, p. 186-187).

En esta inversión y ocultamiento, la "verdad" del "libre" mercado se presenta como uno de los dogmas neoliberales inapelables. Éste se expresa en su ideario educativo en la preeminencia de educación privada, es decir, la "libertad de elección" individual en detrimento de la escuela pública, como principio ideológico articulador de su aspiración sobre la "libertad individual" en contra del bienestar colectivo.

Contraria a esa tendencia extendida en la región, incluso como doctrina constitucional en algunos países de la región, la Revolución Bolivariana propuso una ruta diferente cuando a partir del proceso constituyente de 1999, que trae consigo la aprobación refrendaria del nuevo texto constitucional, impulsa un movimiento político que se materializa en,

[...] el replanteamiento de todo el entramado institucional del Estado... que tuvo especial repercusión en la política educativa, además, se tradujo en un reforzamiento de su posición como garante fundamental de este derecho, tal vez recuperando la esencia de la doctrina del Estado docente expuesta en la constitución de 1948. (CARVAJAL; VILLASMIL SOCORRO, 2018, p. 74).

Las conquistas sociales, entre ellas el derecho a la educación, la transformación de la situación política, económica y social diagnosticada en ese momento, constituyen desde su concepción los elementos estructurantes y al mismo tiempo definitorios de la agenda política del proceso bolivariano. En este sentido, cabe recordar que: 
Se heredaba un escenario minado, favorable a las políticas dirigidas a favorecer la desregulación del sector educativo, producto de las influencias que tuvieron las reformas educativas de corte neoliberal realizadas en la región desde finales de la década de los 70, y que tomó un impulso inusitado en las décadas de los años 80 y 90. (CARVAJAL; VILLASMIL SOCORRO, 2018, p. 74-75).

En este sentido, el proyecto político que emerge con la Revolución Bolivariana, dirigido a atender la situación de precariedad social generalizada presente en la sociedad venezolana, luego de la tierra arrasada dejada por el neoliberalismo, así como las acciones derivadas de éste, representaron entonces y ahora un desafío a la hegemonía imperial. ${ }^{3}$

Entre estas nuevas orientaciones destaca la política exterior bolivariana y la influencia que comienza a ejercer el nuevo liderazgo político en la región, cuestión que representaba un grado superior de desafío a la hegemonía geopolítica de los EE.UU. En este sentido, Pasqualina Curcio (2016) afirma que:

La guerra que actualmente padece el pueblo venezolano constituye un ejemplo histórico más del poder de los grandes capitales, los cuales en busca de su interés político, con el propósito de hacerse del poder, de las riquezas, y muy especialmente de que no se concreten y muestren los logros de modelos alternativos al capitalismo, manipulan visiblemente variables económicas, generan malestar social, socavan el apoyo popular a gobiernos de izquierda, y hacen ver que las distorsiones que estas generan son consecuencia del fracaso de modelos progresistas. (CURCIO, 2016, p. 23).

En consecuencia, la actual coyuntura transcurre en el contexto de una agresión explícita de las élites gubernamentales y económicas de los EE.UU., en contra de Venezuela y sus intereses, en el contexto de una confrontación multiforme, con evidentes implicaciones geopolíticas.

3 Cabe mencionar que desde el Plan Nacional Simón Bolívar (2007 - 2013) hasta el Plan de la Patria (2013 - 2019) la política internacional de Venezuela ha estado orientada al impulso de la conformación de nuevos bloques de poder que venzan las asimetrías y propicien la conformación de un mundo pluripolar y multicéntrico. 


\section{Golpes y contragolpes: breve reseña de la guerra de intervención contra Venezuela}

En el caso venezolano, asistimos a una agresión al uso, es decir, de las ya conocidas en esta y otras realidades en las que los EE.UU. considera que están en peligro sus intereses geoestratégicos. De hecho, se trata de una guerra que sigue formatos conocidos, con muy pocas innovaciones. ${ }^{4}$ Las explicaciones y razones se muestran en los antecedentes de hostilidad de la potencia agresora en contra de aquellas experiencias políticas que no comulgan con sus prédicas e intereses. La lista de agresiones se hace cada vez más extensa, algunos ejemplos sintetizados a continuación, reflejan tal comportamiento:

- Cuba (Desde 1962, la isla caribeña es sometida a un férreo bloqueo.)

- Chile (1970 - 1973, el golpe de Estado que derrocó al presidente Salvador Allende, que inauguró el ciclo de regímenes dictatoriales en el cono sur del continente americano.)

- Nicaragua (A partir de 1979, a partir del triunfo de la Revolución Sandinista hasta la actualidad.)

- Irán e Irak (A partir de 1980, los EE.UU. por intereses geoestratégicos incentiva la confrontación bélica entre ambas naciones. Este capítulo, aún abierto, de la historia contemporánea tuvo su momento álgido con la invasión a Irak en marzo de 2003. En la actualidad, Irán está sometido a una política de sanciones justificada, por EE.UU. y la Unión Europea (UE), por su programa de desarrollo nuclear. Respecto a Irak, en febrero de 2020 el parlamento iraquí exigió la salida de todas las tropas de los EE.UU. de su territorio.)

- Libia (Destruida por la invasión promovida por EE.UU. y amparada por la OTAN, hoy es un país dividido e ingobernable.)

- Siria (Después de una guerra implantada mediante la filtración de grupos terroristas, el pueblo y ejercito de ese país avanzan en la reconquista de sus territorios.)

- República Popular Democrática de Corea (Sometida a un bloqueo por el desarrollo de programa nuclear y armamentístico.)

- Rusia (Sometida a sanciones unilaterales por parte de los EE.UU. debido a su protagonismo en el conflicto ucraniano).

4 Tal vez las innovaciones en este tipo de agresiones vienen dadas por el uso intensivo de las tecnologías de la comunicación e información y con ellas las denominadas "redes sociales", en el énfasis manipulador propio de la guerra psicológica. Pero también, las conocidas fake news y los recovecos de la mentira denominada ahora con el eufemismo de "postverdad". 
En cuanto a Venezuela, la intención ha sido doblegar a través de diversos mecanismos coercitivos la voluntad colectiva de todo un pueblo. En este sentido, resulta reveladora una declaración pública del Departamento de Estado, en la que reconocía que:

La campaña de presión contra Venezuela está funcionando. Las sanciones financieras que hemos impuesto [...] han obligado al Gobierno a comenzar a caer en default, tanto en la deuda soberana como en la deuda de PDVSA, su compañía petrolera. Y lo que estamos viendo [...] es un colapso económico total en Venezuela. Entonces nuestra política funciona, nuestra estrategia funciona y la mantendremos. (SURES ${ }^{5}$; CURCIO, 2019).

En este orden de ideas, William Brownfield ${ }^{6}$ afirmaba:

Debemos tratar esto como una agonía, una tragedia que va a seguir hasta que finalmente llegue a un final [...] y si podemos hacer algo para acelerarlo, debemos hacerlo, pero debemos hacerlo entendiendo que esto va a tener un impacto en millones de personas que ya están teniendo dificultades en encontrar alimentos y medicinas [...] No podemos hacer esto y pretender que no va a tener un impacto, tenemos que tomar una decisión dura, el fin deseado justifica este severo castigo (BROWNFIELD apud CURCIO, 2019).

Kevin Zeese y Margareth Flowers, dejaban clara la intencionalidad de esta política, al sostener que:

Estados Unidos usa sanciones contra países que resisten la agenda de los Estados Unidos. Las sanciones de los Estados Unidos están diseñadas para matar al destruir una economía a través de la denegación de acceso a la financiación, lo que provoca hiperinflación y escasez y bloquea las necesidades básicas, como alimentos y medicamentos. (ZEESE; FLOWERS, 2020).

5 ONG Sures, Estudios Y Defensa en Derechos Humanos.

6 Ex Embajador de EE.UU. en Venezuela y Colombia /12 de octubre de 2018. 
Esta política ha tenido, a parte del relato de voceros protagonistas como los mencionados, resonancia concreta en las decisiones políticas impulsadas por las diferentes administraciones de los EE.UU., y de manera notoria los últimos siete años. Esto significa que esta política se materializó durante los períodos de gobierno de Obama y se intensifica ahora en la era Trump.

El sociólogo Carlos Lanz Rodríguez ha denominado este tipo de agresiones como estrategia de enjambre, debido a la manera multiforme y global de afectar todos los ámbitos de la gestión de gobierno, todos los sectores que integran la economía y la gestión de las políticas públicas. ${ }^{7}$ Hay sobrados ejemplos en las últimas dos décadas de historia reciente venezolana para afirmar que de la larga lista de 198 propuestas del "Método de la Acción No violenta" de Gene Sharp (2011), absolutamente todos, han sido aplicados por operadores políticos nacionales e internacionales para derrocar la alternativa socialista de gobierno.

Una breve cronología permite caracterizar este proceso de agresión, que tiene como punto de partida el año 2014 (Quadro 1).

En concordancia con lo anterior, los principales impactos de estas acciones unilaterales y coercitivas en contra del país, se sintetizan a continuación:

- Bloqueo y confiscación de activos financieros.

- Prohibición de negociación de la deuda de PDVSA.

- Aumento de Riesgo País y costos financieros. (Manipulado por las agencias calificadoras, ej. Standard \& Poor).

- Prohibición de operaciones con oro.

- Prohibición con la criptomoneda venezolana, el Petro.

- Confiscación de activos (CITGO y activos de PDVSA.

- Sanciones al comercio de petróleo.

- Sanciones al Banco Central de Venezuela.

- Multas y penalizaciones administrativas a las operaciones comerciales.

- Prohibición de operaciones aéreas comerciales entre EE.UU. Venezuela.

- Sanciones dirigidas a funcionarios y líderes políticos venezolanos, entre ellas, el hecho de no poder acceder al espacio de la Unión Europeo.

7 Ello se vierte en la afectación de la cotidianidad de los ciudadanos y sus consecuencias esperadas se ubican, ya sea, en la rendición del pueblo en su decisión de apoyar la opción socialista de gobierno a través de masivas protestas sociales o, en grado mayor, la renuncia del presidente ante la falta de apoyo institucional, especialmente de las fuerzas armadas y de amenazas de acciones de incontrolable violencia. 


\section{QUADRO 1 - CRONOLOGÍA DE LA AGRESIÓN}

\begin{tabular}{|c|c|c|c|}
\hline 2014 & 2015 & 2016 & 2017 \\
\hline $\begin{array}{l}\text { En diciembre de ese } \\
\text { año el Congreso de } \\
\text { los EE.UU. aprueba } \\
\text { la "Ley de Defensa } \\
\text { de Derechos Huma- } \\
\text { nos y la Sociedad } \\
\text { Civil de Venezuela"8 }\end{array}$ & $\begin{array}{l}\text { Barack Obama fir- } \\
\text { ma la Orden Ejecu- } \\
\text { tiva (OE) } \mathbf{N}^{\circ} \mathbf{1 3 . 6 9 2} \text {, } \\
\text { de marzo de 2015, co- } \\
\text { nocida como Decreto } \\
\text { Obama, que definió a } \\
\text { Venezuela como una } \\
\text { "amenaza inusual y } \\
\text { extraordinaria" para } \\
\text { la seguridad nacional } \\
\text { y la política exterior } \\
\text { de EE.UU. }\end{array}$ & $\begin{array}{l}\text { En marzo de 2016. La } \\
\text { administración estadouni- } \\
\text { dense, ahora con Donald } \\
\text { Trump al frente, renueva } \\
\text { por un año la Orden Ejecu- } \\
\text { tiva No 13.692. } \\
\text { Entre mayo y agosto de } \\
\text { ese año, bancos de Ale- } \\
\text { mania (Commerzbank), } \\
\text { Portugal (Novo Banco) y } \\
\text { EE.UU. (Citibank) cierran, } \\
\text { congelan o manifiestan la } \\
\text { "imposibilidad" de realizar } \\
\text { operaciones a favor de Ve- } \\
\text { nezuela. } \\
\text { En septiembre de 2016. E1 } \\
\text { gobierno de Venezuela rea- } \\
\text { liza una oferta para canjear } \\
7 \text { mil 100 millones de dó- } \\
\text { lares en bonos de PDVSA } \\
\text { con el fin de aliviar el cro- } \\
\text { nograma de amortización } \\
\text { y refinanciar parcialmente } \\
\text { sus obligaciones. Las tres } \\
\text { grandes calificadoras de } \\
\text { riesgo estadounidenses } \\
\text { atemorizan a los inversio- } \\
\text { nistas con declarar default } \\
\text { (impago) si acceden a la } \\
\text { propuesta venezolana. } \\
\text { En noviembre de 2016. El } \\
\text { banco JP Morgan emite una } \\
\text { falsa alerta de default sobre } \\
\text { un supuesto impago de } \\
\text { deuda de PDVSA de } 404 \\
\text { millones de dólares. }\end{array}$ & $\begin{array}{l}\text { El } 24 \text { agosto de 2017, la } \\
\text { administración Donald } \\
\text { Trump dictó la Orden } \\
\text { Ejecutiva No 13.808, } \\
\text { mediante la cual impuso } \\
\text { un conjunto de medidas } \\
\text { coercitivas y unilaterales } \\
\text { contra la economía y las } \\
\text { finanzas de la República } \\
\text { Bolivariana de Venezuela. } \\
\text { En agosto de 2017. El } \\
\text { banco suizo Credit Suis- } \\
\text { se prohíbe a sus clientes } \\
\text { realizar operaciones fi- } \\
\text { nancieras con Venezuela. } \\
\text { En agosto de 2017. El } \\
\text { banco Bank Of China } \\
\text { (BOC - Panamá), infor- } \\
\text { ma que debido a instruc- } \\
\text { ciones del Departamento } \\
\text { del Tesoro de EEUU y a } \\
\text { presiones del gobierno } \\
\text { panameño, no podrá rea- } \\
\text { lizar ninguna operación } \\
\text { en divisas a favor de Ve- } \\
\text { nezuela. } \\
\text { En octubre de 2017. El } \\
\text { bloqueo financiero de } \\
\text { EEUU imposibilita a Ve- } \\
\text { nezuela depositar en el } \\
\text { banco suizo UBS recur- } \\
\text { sos para vacunas y me- } \\
\text { dicamentos adquiridos a } \\
\text { través del Fondo Rotato- } \\
\text { rio y Estratégico de la Or- } \\
\text { ganización Panamericana } \\
\text { de la Salud. }\end{array}$ \\
\hline
\end{tabular}

FUENTE: Elaboración de los autores (2020). Elaborado a partir de Pasqualina Curcio. Impacto de la Guerra Económica contra el pueblo de Venezuela, 2019.

8 Esta resolución del congreso de los EE.UU., se aprueba partir de la denuncia de sectores opositores venezolanos de la supuesta violación de los derechos humanos, en el contexto de los sucesos ocurridos ese año, liderado por Leopoldo López denominado "La salida". Fueron hechos de violencia de características vandálicas que mantuvieron a regiones del país en estado de conmoción durante meses y que arrojaron 43 fallecidos y más de 800 personas heridas. 
CRONOLOGÍA DE LA AGRESIÓN (CONTINUACIÓN)

\begin{tabular}{|c|c|c|}
\hline 2018 & 2019 & 2020 \\
\hline $\begin{array}{l}\text { Orden Ejecutiva } \mathbf{N}^{\circ} \mathbf{1 3 . 8 2 7} \text {, } \\
\text { de marzo de } 2018 \text {, contra la } \\
\text { criptomoneda Petro. } \\
\text { Orden Ejecutiva } \mathbf{N}^{\circ} \mathbf{1 3 . 8 3 5} \text {, } \\
\text { de mayo de } 2018 \text {, contra las } \\
\text { cuentas por cobrar y otras ope- } \\
\text { raciones de Venezuela. } \\
\text { Orden Ejecutiva } \mathbf{N}^{\circ} \mathbf{1 3 . 8 5 0} \text {, } \\
\text { de noviembre de } 2018 \text {, contra } \\
\text { las operaciones de comercia- } \\
\text { lización del oro de Venezuela. }\end{array}$ & $\begin{array}{l}\text { Orden Ejecutiva } \mathbf{N}^{\circ} \mathbf{1 3 . 8 5 7} \text {, } \\
\text { del } 28 \text { de enero de } 2019 \text {, que } \\
\text { establece el bloqueo - con- } \\
\text { gelamiento de los activos de } \\
\text { PDVSA (CITGO) en EEUU. } \\
\text { Orden Ejecutiva } N^{\circ} \mathbf{1 3 . 8 8 4} \text {, } \\
\text { del } 5 \text { de agosto de } 2019 \text {, que } \\
\text { formaliza el bloqueo de ope- } \\
\text { raciones de la línea aérea } \\
\text { CONVIASA. }\end{array}$ & $\begin{array}{l}\text { El } 7 \text { de febrero el Departa- } \\
\text { mento del Tesoro, a través } \\
\text { de la Oficina de Control de } \\
\text { Activos Extranjeros (OFAC), } \\
\text { formaliza las sanciones con- } \\
\text { tra la línea aérea venezolana, } \\
\text { en atención a la OE 13.884, } \\
\text { que intenta inmovilizar a } 40 \\
\text { aeronaves de la empresa ve- } \\
\text { nezolana. }\end{array}$ \\
\hline
\end{tabular}

FUENTE: Elaboración propia (2020). Elaborado a partir de Pasqualina Curcio. Impacto de la Guerra Económica contra el pueblo de Venezuela, 2019.

Estas operaciones de guerra fueron orientadas, fundamentalmente, a lesionar el aparato económico - productivo del país, con innumerables y aún no bien ponderados efectos en la sociedad venezolana. Esta afirmación la sintetizamos a partir del aporte de los precitados Zeese y Flowers quienes testifican que:

En Venezuela, debido a las sanciones, 180.000 operaciones médicas han sido canceladas y 823.000 pacientes con enfermedades crónicas esperan medicamentos. El Centro de Investigación Económica y Política descubrió que las sanciones han privado a Venezuela de «miles de millones de dólares en divisas necesarias para pagar las importaciones esenciales y que salvan vidas», lo que contribuye a 40.000 muertes totales en 2017 y 2018. Más de 300.000 venezolanos están en riesgo debido a la falta de acceso a medicamentos o tratamientos. Los economistas advierten de que las sanciones estadounidenses podrían causar hambruna en Venezuela. Las sanciones también causan escasez de piezas y equipos necesarios para la generación de electricidad, sistemas de agua y transporte, además de evitar la participación en el mercado financiero mundial. (ZEESE; FLOWERS, 2020, subrayados en el original).

Otra muestra del impacto de las acciones unilaterales y coercitivas de los EE.UU. contra Venezuela se observan en distintos ámbitos de la actividad política, social, cultural, comercial y empresarial del país. Muestra de ello es que 
son objeto de sanciones: más de 60 empresas extranjeras con intereses en el país, 9 empresas del Estado y otras 9 asociadas con el gobierno venezolano; 41 aviones de Conviasa ${ }^{9}$ y 15 de Petróleos de Venezuela S.A. (PDVSA); además, 40 buques pertenecientes de la empresa petrolera y 9 buques de armadores extranjeros. Además, también son blanco de estas medidas 133 funcionarios venezolanos y sus familiares, así como 22 personas naturales por "tener relaciones" con el gobierno venezolano ${ }^{10}$.

Estás medidas unilaterales coercitivas tienen un efecto sistémico devastador en la sociedad venezolana. Una de las explicaciones de estos efectos se encuentra en el impacto de la agresión en contra de la industria petrolera venezolana que, de acuerdo con la gráfica que sigue a continuación, observa una caída vertiginosa de más del $90 \%$ de los ingresos que ésta genera al tesoro nacional.

\section{FIGURA 1 - INGRESO EN DIVISAS DE LA REPÚBLICA}

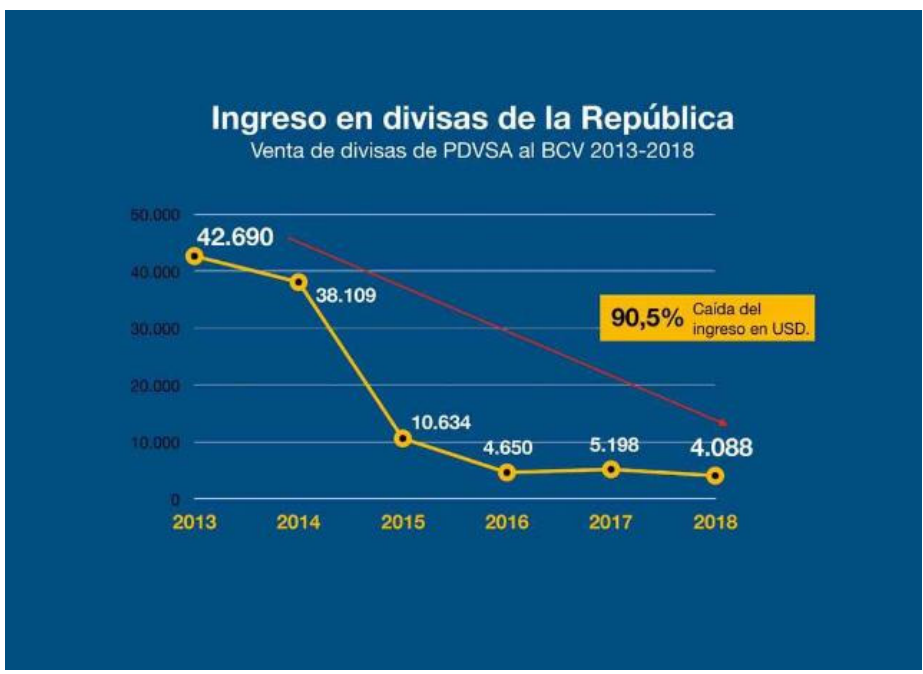

FUENTE: Ministerio del Poder Popular para la Comunicación y la Informácion (MIppCi), 2020.

Este hecho tiene especial repercusión en la dinámica económica del país, debido a la ya mencionada alta dependencia de ésta a la industria petrolera y a todos los procesos asociados a esta actividad industrial. Este primer gran impacto permea al resto de las dinámicas sociales, políticas, productivas y culturales

10 Disponible en: http://www.minci.gob.ve/presidencial/. Acceso en: 26 mayo. 2020. 
del país, constituyéndose en una verdadera tormenta perfecta que incide de forma determinante en áreas tan sensibles como la salud ${ }^{11}$, la alimentación ${ }^{12} \mathrm{y}$ la educación.

Las vulnerabilidades de nuestra economía e instituciones estaban a la vista. El propio Brownfield avizoraba que:

Si vamos a sancionar a PDVSA, ello tendrá un impacto en el pueblo entero, en el ciudadano común y corriente. El contra argumento es que el pueblo sufre tanto por la falta de alimentación, seguridad, medicinas, salud pública, que en este momento quizás la mayor resolución sería acelerar el colapso, aunque ello produzca un periodo de sufrimiento de meses o quizás años. (BROWNFIELD apud CURCIO, 2019).

Zeese y Flowers (2020), ya citados, sostienen que este tipo de políticas sancionatorias usualmente son el preludio a las acciones militares. Este comentario adquiere especial importancia en el contexto de la agudización de la política beligerante del imperialismo, que presiona con sanciones a terceros ${ }^{13}$, así como a empresas navieras que transporten productos desde y para Venezuela; pero, que va más allá, al incorporar a países vecinos (Brasil y Colombia) en el esquema de la agresión directa.

Recientemente, en 21 de noviembre de 2019, la Organización para las Naciones Unidas (ONU) aprobó por mayoría la resolución "Medidas económicas unilaterales como medio de ejercer presión política y económica sobre los países en desarrollo", en la que reconoce que "[...] las medidas económicas coercitivas unilaterales constituyen una flagrante violación de los principios del Derecho Internacional y la Carta de las Naciones Unidas"14.

Resulta curioso, cuando no contradictorio, que este tipo de políticas coercitivas implementadas de manera unilateral por los EE.UU., y seguidas acríticamente por el auto denominado "Grupo de Lima", resultan violatorias hasta de su propio ordenamiento jurídico, debido a que la justificación sobre la

11 La tasa de mortalidad materna se incrementó de 68,66 en 2013 a 135,22 en el año 2017. Disponible en: http://www.minci.gob.ve/las-sanciones-son-un-crimen/. Acceso en: 26 mayo. 2020.

12 La prevalencia de subalimentación pasó de 2,0\% en 2013 a 13,4\% en 2018. Disponible en: http://www.minci.gob.ve/las-sanciones-son-un-crimen/. Acceso en: 26 mayo. 2020.

13 Disponible en: https://www.bbc.com/mundo/noticias-america-latina-51409950. Acceso en: 26 mayo. 2020.

14 Disponible en: https://www.telesurtv.net/news/onu-rechaza-imposicion-medidasunilaterales-20191121-0026.html. Acceso en: 26 mayo 2020. 
supuesta "amenaza inusual y extraordinaria" que en teoría representa Venezuela para ese país, sólo sería válida en que éste (EE.UU.) se encontrara inmerso en una "emergencia nacional", cuestión que no es el caso. ${ }^{15}$

El 13 de febrero de 2020, el gobierno venezolano interpuso una denuncia ante la Corte Penal Internacional,

[...] para que se investiguen los graves delitos cometidos contra la población venezolana por parte del Gobierno de Estados Unidos, debido a la imposición de un bloqueo económico y de medidas coercitivas unilaterales denominadas, eufemísticamente, 'sanciones'. (MINISTERIO DEL PODER POPULAR PARA LA COMUNICACIÓN E INFORMACIÓN, 2020). ${ }^{16}$

\section{Políticas públicas sociales y educación en tiempos de guerra}

Después de dos décadas de revolución se puede afirmar que en Venezuela se originó un verdadero proceso de cambio social ${ }^{17}$ que imprimió un nuevo

15 Disponible en: https://popularresistance.org/us-sanctions-on-venezuela-illegal-underun-oas-and-us-law/. Acceso en: 26 mayo 2020.

16 Disponible en: http://www.minci.gob.ve/las-sanciones-son-un-crimen/. Acceso en: 26 mayo 2020 .

17 George Lakoff (2007), explica en su obra "No pienses en un elefante" los mecanismos cognitivos que intervienen en los procesos de cambio social. Su campo de análisis se ubica en la lingüística cognitiva y desde allí estudia la acción política en la que se involucran dispositivos conceptuales y lingüísticos que generan marcos de sentido a través de los cuales los individuos comprenden y actúan en el mundo. Explica que los marcos conceptuales se ubican en el inconsciente cognitivo, se refiere a estructuras cerebrales que solo se pueden analizar en la medida en que se detectan las formas de razonar, el sentido común y los contenidos discursivos, es decir, solo se puede conocer lo que una persona piensa cuando exterioriza su pensamiento en las acciones comunicativas tales como hablar, escribir, actuar. Este autor, al analizar los procesos políticos de los partidos republicano y demócrata de Estados Unidos va esbozando las relaciones existentes en los cambios de marcos conceptuales colectivos y los procesos de cambio social. Ahora bien, si se analiza el fenómeno político del chavismo bajo las premisas de Lakoff, podemos afirmar que en Venezuela el proceso de nuevas formas de concebir las políticas públicas sumado a la introducción de un nuevo lenguaje en el que se introducen significados asociados con: democracia participativa, pueblo, patria, poder popular, comunidad, comuna, derechos sociales, conquistas populares, historia, justicia social, Bolívar, bolivarianismo, socialismo, público, revolución, entre una larga lista de conceptos que van unido nuevas configuraciones sociales e institucionales, sin dudas, han ido generando verdaderos procesos de cambio social. El comandante Chávez introdujo en el imaginario social conceptos contradictorios a aquellos surgidos del repertorio capitalista, construyó un nuevo lenguaje y nuevos 
discurso y acción política con orientaciones antineoliberales en la forma de gestión de la economía y de las políticas de protección social. Expresión de estas transformaciones se encuentra en la praxis política emergente, en la que conceptos como el de gasto público se superan para concebir la política de atención a las necesidades y demandas (y deuda acumulada con el pueblo) del pueblo como parte de la inversión del Estado, o lo que se reconoce como contraparte del gasto público, la inversión social ${ }^{18}$.

Este asunto no es un detalle menor pues es aquí donde se concentra el hito secular de la lógica de expoliación capitalista que, históricamente, ha cuestionado las políticas redistributivas sobre las ganancias o plusvalía del capital. En consecuencia, este constituye el asunto medular de la lucha de clases, en el sentido, del despojo sistemático de la fuerza de trabajo y de los recursos espirituales de las personas, para favorecer la dinámica metabólica del capital, de acuerdo con el planteamiento de István Mészáros (2009). Venezuela, como parte del entramado sistema-mundo ${ }^{19}$, realiza una apuesta política por romper la dinámica de concentración monopólica del capital local y global, en el sentido de implementar políticas redistributivas de la renta, en este caso petrolera, y fortalecer las capacidades materiales y espirituales de los sectores históricamente excluidos.

protagonistas, de allí que pueda afirmarse que creó nuevos marcos de interpretación de la vida en sociedad y de la relación de los ciudadanos con el Estado y las instituciones. Lo mismo ocurre con las formas de mirarse como pueblo venezolano ante los poderes hegemónicos mundiales, un ejemplo claro está en la inmortalización de la frase lanzada en la Asamblea General de Naciones Unidas: "huele a azufre" con la que el presidente, hecho pueblo latinoamericano, demoniza al imperio estadounidense representado para entonces por el expresidente George Bush. De manera que, la articulación de un discurso de significaciones humanistas, bolivarianas y socialistas, comunicadas de manera eficiente a través de las tecnologías de la ecología mediática, destinadas a la reivindicación de los excluidos y estructuradas a un nuevo orden social e institucional, dio como resultado un cambio social que se traduce en la revolución bolivariana.

18 La noción de gasto público deja en manos del mercado las políticas sociales, pero para los mercados el gasto público no genera beneficios, de allí la tendencia a mercantilizar los servicios públicos, prácticas que han sido muy cuestionadas porque generan la exclusión de los sectores más vulnerables con respecto al acceso a los servicios públicos (salud, educación, recreación, transporte, acceso al agua potable, electricidad, vivienda, entre otros). El paradigma antineoliberal de crecimiento con equidad reformula esta noción por la de inversión social. Se desmarca de los lineamientos de los organismos multilaterales (FMI y BM) y asume al Estado como garante de las políticas sociales para reducir la desigualdad.

19 Aquí se recupera el sentido de la categoría sistema-mundo desarrollada por el sociólogo y pensador estadounidense Immanuel Wallerstein. 
En el caso venezolano, la inversión social ${ }^{20}$ tiene especial repercusión debido al carácter vinculante de ésta con la doctrina y el resto de la arquitectura política del proyecto bolivariano, que ubica a las necesidades del pueblo en el centro de la gestión. De acuerdo con la Comisión Económica para América Latina $(\text { CEPAL })^{21}$, para el año 2015 esta inversión alcanzaba el 18.8\% del Producto Interior Bruto (PIB), que representaba en torno al $60 \%$ del presupuesto nacional; en materia educativa esta inversión llegaba al $5.8 \%$ del PIB. Para 2019, se percibe, pese a la merma de ingresos producto de las medidas unilaterales y coercitivas del bloqueo como parte la guerra económica, el incremento de la inversión social en el presupuesto de la nación hasta alcanzar el 75.9 \%. Esta evolución favorable en la inversión educativa se refleja en un aumento hasta el $7 \%$ del PIB.

La primera característica destacable en la doctrina educativa venezolana es la consideración de la educación como derecho humano y deber social fundamental, así mismo, se asume la gratuidad y obligatoriedad como una condición sine qua non para el aseguramiento de este derecho. Así queda expresado en el artículo 102 de la constitución de la república:

Artículo 102. La educación es un derecho humano y un deber social fundamental, es democrática, gratuita y obligatoria. El Estado la asumirá como función indeclinable y de máximo interés en todos sus niveles y modalidades, y como instrumento del conocimiento científico, humanístico y tecnológico al servicio de la sociedad [...]. (VENEZUELA, 1999).

La disposición de otros derechos sociales en la Carta Magna, se conjugan para garantizar el derecho a la educación, se pueden mencionar en este caso aquellos vinculados con la igualdad social, la protección a la familia y los que potencian el desarrollo de una educación de calidad y para todos. Así mismo, en los principios y fines del Estado desarrollados en la constitución queda manifiesto el lugar de la educación como el fundamento de construcción de la sociedad igualitaria, justa y participativa sobre la cual erigir el nuevo modelo de Estado social de justicia y de derecho.

20 En el caso venezolano, en el apartado sobre la "Inversión social" se incluyen: Economía productiva, Salud, Seguridad alimentaria, Vivienda, Desarrollo urbano, Servicios, Plataforma Social Patria, Educación, Ciencia y Tecnología.

21 Disponible en: https://observatoriosocial.cepal.org/inversion/es/paises/venezuela Acceso en: 26 mayo 2020. 
Artículo 3. El Estado tiene como fines esenciales la defensa y el desarrollo de la persona y el respeto a su dignidad, el ejercicio democrático de la voluntad popular, la construcción de una sociedad justa y amante de la paz, la promoción de la prosperidad y bienestar del pueblo y la garantía del cumplimiento de los principios, derechos y deberes reconocidos y consagrados en esta Constitución. La educación y el trabajo son los procesos fundamentales para alcanzar dichos fines (VENEZUELA, 1999, el subrayado es nuestro).

Estos fines constitucionales están consustanciados con los principios y valores de la educación contemplados en la Ley Orgánica de Educación (2009):

Artículo 3. La presente Ley establece como principios de la educación, la democracia participativa y protagónica, la responsabilidad social, la igualdad entre todos los ciudadanos y ciudadanas sin discriminación de ninguna índole [...]. (VENEZUELA, 2009).

El marco legal de la educación venezolana se orienta a la promoción y defensa del tipo de democracia participativa y protagónica y del modelo de Estado democrático, social de derecho y de justicia. Sobre esta base se constituye el Sistema de Educación pública, gratuita y obligatoria y se formulan las políticas educativas. El desarrollo de políticas públicas educativas durante las dos décadas de este siglo, han garantizado el acceso a la educación para todos, pero no cualquier educación, sino aquella que forme "[...] para la independencia, la libertad y la emancipación, la valoración y defensa de la soberanía [...]" (VENEZUELA, 2009).

Podemos mencionar, entre otras, tres grandes políticas que pueden considerarse la base de profundas transformaciones educativas por su impacto en todos los sectores sociales y en toda la geografía nacional.

A) La transformación curricular expresada en el Currículo Bolivariano y en la dotación de los textos escolares para estudiantes y docentes "Colección Bicentenario", con lo cual el Estado se propone impactar en la praxis docente, orientando la pedagogía hacia enfoques críticos enraizados en los aportes de pedagogos nuestroamericanos y en la acción educativa contextualizada en las necesidades locales y características socioculturales de los diversos contextos escolares.

B) La democratización de la tecnología y el uso de plataformas digitales para el acceso a la información y las telecomunicaciones a través del programa 
Canaima, considerado por la Unesco una experiencia digna de ser replicada en la región.

C) La organización y gestión escolar sustentada en la participación comunitaria fortaleciendo los vínculos entre escuela y comunidad y otorgando a la escuela y a los procesos educativos un lugar preponderante en la formación para el ejercicio de la democracia participativa y protagónica.

En la actual coyuntura económica todas las políticas de Estado en favor del bienestar del pueblo han sido afectadas por la aplicación del bloqueo financiero y las medidas coercitivas unilaterales e ilegales sobre el país. Las múltiples denuncias de la diplomacia venezolana ante la Unesco y otros organismos de cooperación internacional han estado dirigidas al justo reclamo por la prevalescencia del Derecho Internacional sobre el principio de no injerencia en los asuntos internos de un país, del respeto a la soberanía y la integridad territorial de los Estados y a la autodeterminación de los pueblos. ${ }^{22}$ No obstante, es importante reconocer dos aspectos que han tenido una decisiva repercusión en la atención a las consecuencias de la guerra contra el pueblo venezolano y en la minimización del impacto del bloqueo financiero en el ejercicio del derecho a la educación.

Uno de ellos corresponde a las características del Estado respecto a su posicionamiento político antiimperialista y humanista, lo cual ha permitido que, pese a la profunda merma de recursos económicos, ninguna de las políticas dirigidas a favorecer a las mayorías sociales se ha restringido, tal vez ralentizado por efecto de la caída o bloqueo del ingreso nacional. El segundo aspecto corresponde a la existencia de un tejido social organizado. En este último aspecto, cabe aclarar que las organizaciones populares en Venezuela no obedecen a la acción voluntarista espontánea o esporádica de un grupo de personas, sino que responden al tipo de democracia que queda explícita en la doctrina del texto constitucional, que se traduce en los principios de participación y corresponsabilidad social, sustentadas desde el punto de vista jurídico en las Leyes del Poder Popular y materializado por el emergente tejido social organizado. De manera que la acción comunal del Estado en articulación con la sociedad comunal en construcción ha generado mecanismos sinérgicos para la resistencia, al tiempo que en una dura y trabajosa marcha se avanza en la emergente arquitectura política y social de Venezuela.

22 Puede consultarse en la página web: Prensa Venezuela en la Unesco, bajo el titular: Venezuela denuncia ante la Unesco impacto de medidas coercitivas unilaterales de EEUU, escrito por Enio Melean. 


\section{Notas finales}

En este orden de ideas, la reconversión e iniciativa del Estado involucra la repolitización de la sociedad, como condición para garantizar la participación organizada del pueblo, de las comunidades, para su concurso efectivo en el proceso de concepción y desarrollo de las políticas públicas. ${ }^{23}$ Este hecho político viene de la mano de acciones jurídico-políticas materializadas en la concepción y aprobación parlamentaria de las leyes del poder popular. Este cuerpo normativo sirve de referente para la actuación del pueblo organizado en el complejo entramado de las políticas públicas.

Esta experiencia constituye uno de los pilares en la evolución política de la Revolución Bolivariana, por tanto, cuerpo y sentido de la acción política que el proyecto revolucionario plantea en los fundamentos de su doctrina. La acción del Estado como construcción histórico social situada debe comprenderse en estas dimensiones culturales. De igual manera, las políticas públicas sociales $\mathrm{y}$, concretamente, las educativas, se desarrollan en este marco, generando, como reacción de los factores hegemónicos, un proceso de agudización de la lucha de clases, que se observó fundamentalmente a principios de siglo, en el reagrupamiento de la derecha política y cultural en diferentes plataformas de acción dirigidas a torpedear las iniciativas del gobierno bolivariano, como expresión revolucionaria emergente.

La recuperación de la iniciativa pública en materia educativa corresponde a los esfuerzos dirigidos a fortalecer los vínculos escuela-comunidad, como parte de la reorganización de otros vínculos como, por ejemplo, el de las comunidades con el poder político constituido, es decir, la siempre compleja relación del pueblo con las instituciones. Una muestra de ello es la conformación de los Consejos Educativos.

Esta realidad convida a repensar la cotidianidad, a entender que la actual situación obedece a un período excepcional de la vida republicana y, en consecuencia, las acciones políticas deben interpretar este momento histórico. Así como los organismos del Estado, fundamentalmente, del Poder Ejecutivo, deben realizar una acuciosa auditoría sobre los daños materiales producto de la política de bloqueo de la administración Trump en contra de Venezuela. De igual manera, se debe precisar los impactos sociales y espirituales de esa política en el tejido social venezolano.

23 Cabe resaltar que este factor político es una de las claves de la resistencia del pueblo venezolano ante la agresión imperial y de sus lacayos. 


\section{REFERENCIAS}

BORON, Atílio. El hechicero de la tribu. Mario Vargas Llosa y el liberalismo en América Latina. Caracas: Monte Ávila Editores Latinoamericana, 2019. (Colección Milenio Libre).

CARVAJAL RUIZ, Samuel H.; VILLASMIL SOCORRO, Paulina E. La educación venezolana en el contexto de desarrollo de las tensiones ente lo público y lo privado. En: PERONI, Vera Maria Vidal; LIMA, Paula Valim; KADER, Carolina Rosa (org.). Redefiniciones de las fronteras entre lo público y lo privado: Implicaciones para la democratización de la educación. São Leopoldo: Editora Oikos, 2018, p. 61-78.

CELAG (Centro Estratégico Latinoamericano de Geopolítica). Las consecuencias económicas del boicot a Venezuela. Disponible en: https://www.celag.org/lasconsecuencias-economicas-del-boicot-venezuela/, 2019. Acceso en: 20 jun. 2019.

CURCIO, Pasqualina. La mano visible del Mercado. Guerra económica en Venezuela. Caracas: Editorial Nosotros Mismos, 2016.

CURCIO, Pasqualina. Impacto de la guerra económica contra el pueblo de Venezuela, 2019. Disponible en: https://www.15yultimo.com/2019/03/18/impacto-de-la-guerraeconomica-contra-el-pueblo-de-venezuela/. Acceso en: 20 jun. 2019.

CURCIO, Pasqualina. Impacto de la Guerra Económica contra el pueblo de Venezuela. Red Angostura, 06 ago. 2019. Disponible en: http://redangostura.org.ve/?p=1153 Acceso en: 5 jun. 2020.

LAKOFF, George. No pienses en un elefante. Lenguaje y debate político. Madrid: Editorial Complutense, UCM, 2007.

MÉSZÁROS, István. La crisis estructural del capital. Caracas: MINCI, 2009.

MINISTERIO DEL PODER POPULAR PARA RELACIONES EXTERIORES.10 puntos claves para entender la acción llevada adelante por Venezuela en defensa de la soberanía nacional y los derechos humanos del pueblo venezolano. 2020. Disponible en: http://mppre.gob.ve/10-claves-contra-sanciones-criminales/ Accesso en: 26 mayo 2020.

MINISTERIO DEL PODER POPULAR PARA LA COMUNICACIÓN E INFORMACIÓN. Ingreso de divisas cayó 90,5\% a causa de las medidas coercitivas contra PDVSA. 06 mar. 2020. Disponible en: http://www.minci.gob.ve/ingreso-dedivisas-cayo-905-a-causa-de-las-medidas-coercitivas-contra-pdvsa/ Acceso en: 26 mayo. 2020.

MINISTERIO DEL PODER POPULAR PARA LA COMUNICACIÓN E INFORMACIÓN. Las Sanciones son un crimen. 03 mar. 2020. Disponible en: http:// www.minci.gob.ve/las-sanciones-son-un-crimen/. Acceso en: 26 mayo. 2020.

OLMO, Guillermo D. EE.UU. sanciona a Rosneft: cómo ayuda la petrolera a Nicolás Maduro y por qué es clave en el nuevo pulso entre Estados Unidos y Rusia en Venezuela. 
BBC News Mundo, 07 feb. 2020. Disponible en: https:/www.bbc.com/mundo/noticiasamerica-latina-51409950 Acceso en: 26 mayo 2020

ONU rechaza imposición de medidas económicas unilaterales. Telesurtv, 22 nov. 2019. Disponible en https://www.telesurtv.net/news/onu-rechaza-imposicion-medidasunilaterales-20191121-0026.html. Acceso en: 26 mayo 2020.

SHARP, Gene. De la dictadura a la democracia. Un sistema conceptual para la liberación. The Albert Einstein Institution. Estados Unidos de América, 2011.

SURES; CURCIO CURCIO, Pasqualina. Venezuela: bloqueo económico como arma de guerra y crimen de lesa humanidade. Brasil de Fato. 06 mayo 2019. Disponible en https://www.brasildefato.com.br/2019/05/06/articulo-orvenezuela-bloqueo-economicocomo-arma-de-guerra-y-crimen-de-lesa-humanidad. Acceso em: 14 ago. 2020.

Us sanctions on Venezuela illegal under un, oas and us law. Popular Resitance.org. 26 jun. 2019. Disponible en: https://popularresistance.org/us-sanctions-on-venezuela-illegalunder-un-oas-and-us-law/. Acceso en: 26 mayo 2020.

VENEZUELA. Constitución de la República Bolivariana de Venezuela, 1999.

VENEZUELA. Ley Orgánica de Educación, 2009.

VENEZUELA. Declaración del Departamento de Estado de EEUU, 9 enero 2018.

VENEZUELA. Portal de inversión social en América Latina y el Caribe. Disponible en: https://observatoriosocial.cepal.org/inversion/es/paises/venezuela Acceso en: 26 mayo 2020.

VENEZUELA: bloqueo económico como arma de guerra y crimn de lesa humanidade. Brasil de Fato, 2019. Disponible en: https:/www.brasildefato.com.br/2019/05/06/ articulo-orvenezuela-bloqueo-economico-como-arma-de-guerra-y-crimen-de-lesahumanidad. Acceso en: 26 mayo 2020.

ZEESE, Kevin; FLOWERS, Margareth. El mundo debe poner fin a la guerra económica ilegal de los Estados Unidos, 2020. Disponible en: https://rebelion.org/el-mundo-debeponer-fin-a-la-guerra-economica-ilegal-de-los-estados-unidos/. Acceso en: 26 mayo 2020.

Texto recibido en 23/07/2020.

Texto aprobado en 18/09/2020. 